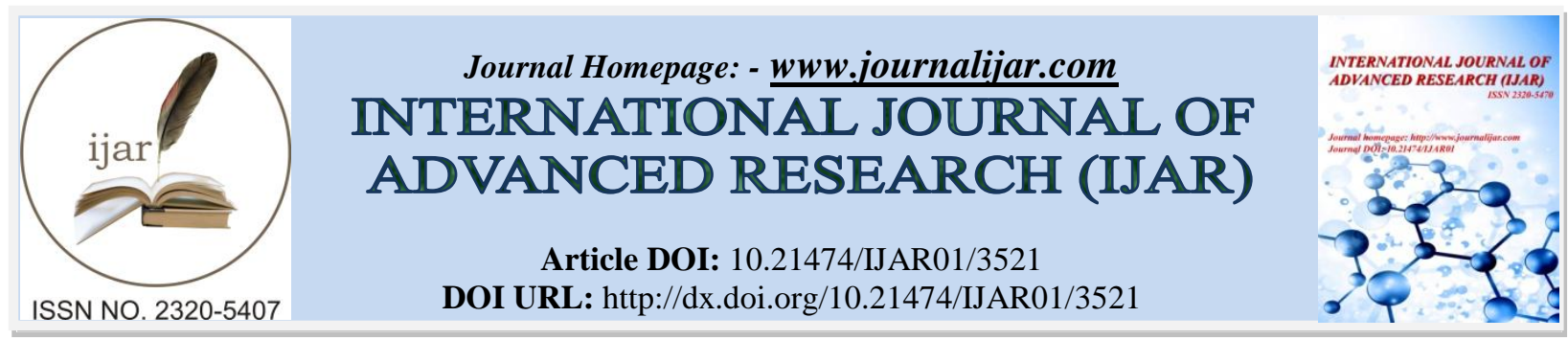

RESEARCH ARTICLE

\title{
A CLINICAL STUDY TO COMPARE THE EFFICACY OF AUTOLOGUS PLATELET RICH PLASMA (PRP) VERSUS NORMAL SALINE DRESSING IN CHRONIC NON-HEALING ULCERS
}

\author{
Dr. S. Sivakumar. Mch ${ }^{1}$, Prof. B. Asokan. $\mathrm{Mch}^{2}$, Prof . V. P. Ramanan. $\mathrm{Mch}^{3}$, \\ Dr. M. Sundrarajan .Mch ${ }^{3}$. \\ 1. Assistant professor, Dept. Of Plastic Surgery, Government Medical College and ESI Hospital, Coimbatore, \\ 2. Professor Of Plastic Surgery \&Dean Government Medical College and ESI Hospital, Coimbator
}

3. Associate Professor.Dept. Of Plastic Surgery-CMCH,Coimbatore

\section{Manuscript Info}

[........................

Manuscript History

Received: 20 January 2017

Final Accepted: 21 February 2017

Published: March 2017

\section{Key words:-}

Chronic non healing ulcers; Autologous

platelet rich plasma (PRP); platelet

derived growth factors; wound

reduction.

\section{Abstract}

Copy Right, IJAR, 2017,. All rights reserved.

\section{Introduction:-}

Skin ulcers are defined by the loss of tissue that includes the epidermis and the dermis, at times affecting the adipose tissue and the muscle fascia. There is not spontaneous recovery and the tissue lesion many times results in a fibrous scar [1]. Skin ulceration is a clinical problem, with an incidence of $0.78 \%$. The financial cost of treatment of such wounds is enormous [2]. Several etiological factors are associated to the development of this condition, such as: chronic venous disease, peripheral arterial disease, neuropathy, physical trauma, hematologic disorders, skin infection, inflammatory diseases, neoplasia, nutritional and iatrogenic alterations. The healing process is dynamic and involves complex events that include hemostasis, inflammation, granulation tissue formation, epithelialization, neovascularization, collagen synthesis, and wound contraction. It involves a sequence of events that begin at the moment of injury and continue for several subsequent months and can be divided into three stages: inflammation, proliferation and remodeling [3]. Several experimental clinical studies have demonstrated the reduction of growth factors of chronic wounds. Platelet aggregation has the leading role in the process of skin healing since it is responsible for releasing growth factors, adhesion molecules and lipids, which regulate migration, proliferation and function of keratinocytes, fibroblasts and endothelial cells [4, 5]. The analysis of supernatant of chronic wounds compared to acute wounds revealed a considerable decrease of the growth factors in the former, observing a quick metabolization of the growth factors due to proteases found in the wound, of bacterial or cellular source. On the other hand, in diabetic ulcers and due to venous insufficiency, the decrease of the growth factors occurs due to a mechanism of sequestrum by fibrin around the capillaries [6]. Therefore, biological stimulation of the wound with platelet rich plasma (PRP) (which drives the most important factors for skin and tissue repair) has been recently introduced as a possible alternative to complex surgical methods. 


\section{Autologous Platelet-rich plasma (PRP):-}

The application of PRP has been documented first promoted by M. Ferrari in 1987 as an autologous transfusion component after an open heart operation to avoid homologous blood product transfusion.

PRP can be defined as the volume fraction of blood plasma contains high concentration of platelets, from a baseline serum level. PRP is mainly a platelet concentrate with minor proportions white blood cells and other blood components [10]. A concentration of $1,407,640 \mathrm{cells} / \mu \mathrm{l}$ (with a standard deviation of 320,100) has been suggested as ideal for the definition of PRP [10]. This number corresponds to a platelet count about 4-5 times higher than that contained in the blood, it usually ranges from 150,000 for the $350.000 / \mu 1$ (approximately an average value around $200.000 / \mu 1)[11]$.

PRP also called as platelet-enriched plasma, platelet-rich concentrate, autologous platelet gel, and platelet releasate [7]. Platelet rich plasma have been used to treat wounds since 1985 [9]. PRP serves as a growth factor agonist [10] and has both mitogenic and chemotactic properties $[8,9]$. PRP contains a high level of clotting and growth factors [7].

The mechanism of action for PRP is thought to be the molecular and cellular induction of normal wound healing response similar to that seen with platelet activation [12]. PRP accelerate all phases of wound healing (most prominent in angiogenesis) [12].

PRP used in the treatment of chronic skin and soft tissue ulcerations in addition to the use of PRP include dental and oral surgery faciomaxillary surgery orthopedic surgery and trauma], plastic and cosmetic surgery spinal surgery heart bypass surgery and burns surgery

Autologous PRP is a new biotechnology that has stimulation and acceleration of soft-tissue healing.

PRP provides as a surgical hemostatic agent that is biocompatible, safe, and effective. PRP enhances the hemostatic response to injury and accelerates epithelial endothelial and epidermal regeneration, stimulates angiogenesis, enhances collagen synthesis, promotes soft tissue healing, decreases dermal scarring and reverses the inhibition of wound healing caused by glucocorticoids. The high leukocyte concentration of PRP has antimicrobial effect. Since PRP is an autologous blood product, it carries no risk of transmitting infectious disease.

In PRP with chronic non-healing wounds, it has also been used as an anti angiogenic agent and as a carrier for growth factors. In surgical settings, PRP decreases the frequency of intraoperative and postoperative bleeding at donor and recipient sites, accelerates soft-tissue healing, supports the initial stability of grafted tissue at recipient sites as a result of its cohesive and adhesive nature, promotes rapid vascularization of healing tissue by delivering growth factors and, when used in combination with bone replacement materials, induces regeneration.

\section{Growth Factors:-}

PRP exerts effects via the degranulation of the alpha granules in platelets that contain growth factors. When the platelets in PRP are activated by thrombin, they release growth factors and serve to accelerate the wound-healing process by promoting cellular proliferation, matrix formation, osteoid production, connective tissue healing, angiogenesis, and collagen synthesis.

The active secretion growth factors begins within minutes of the start of the coagulation sequence and more than $90 \%$ are secreted during the first hour, remaining growth factors for the 7 days of their viability. . The rate of wound healing is determined by the number of platelets in the blood clot and PRP increases that initial number.

\section{Methodology:-}

This is a prospective randomized controlled study to test the efficacy of autologous platelet rich plasma versus normal saline dressing in chronic non-healing. This study was conducted in our medical college hospital for a period of one year from January 2015 to December 2015 in the department of plastic Surgery 20 cases were studied for chronic non healing ulcers with autologous platelet rich plasma and 20 cases for conventional method who received normal saline as dressing for chronic non healing ulcers. Patients were randomized according to random number table. 
20 patients received autologous platelet rich plasma and 20 patients received conventional method (Wet normal saline dressing). The Inclusion criteria includes

Patients in the age group of 18 to 80 years with long standing non-healing ulcers

(pressure sores, diabetic ulcers, venous ulcers, other non-specific ulcers),

Non-diabetic patients and patients with type 1 or type 2 diabetes mellitus,

Ulcer $\geq 4$ weeks duration and,

Ulcer $\leq 100 \mathrm{~cm} 2$ in size,

$\mathrm{Hb} \geq 10 \mathrm{~g} \%$.

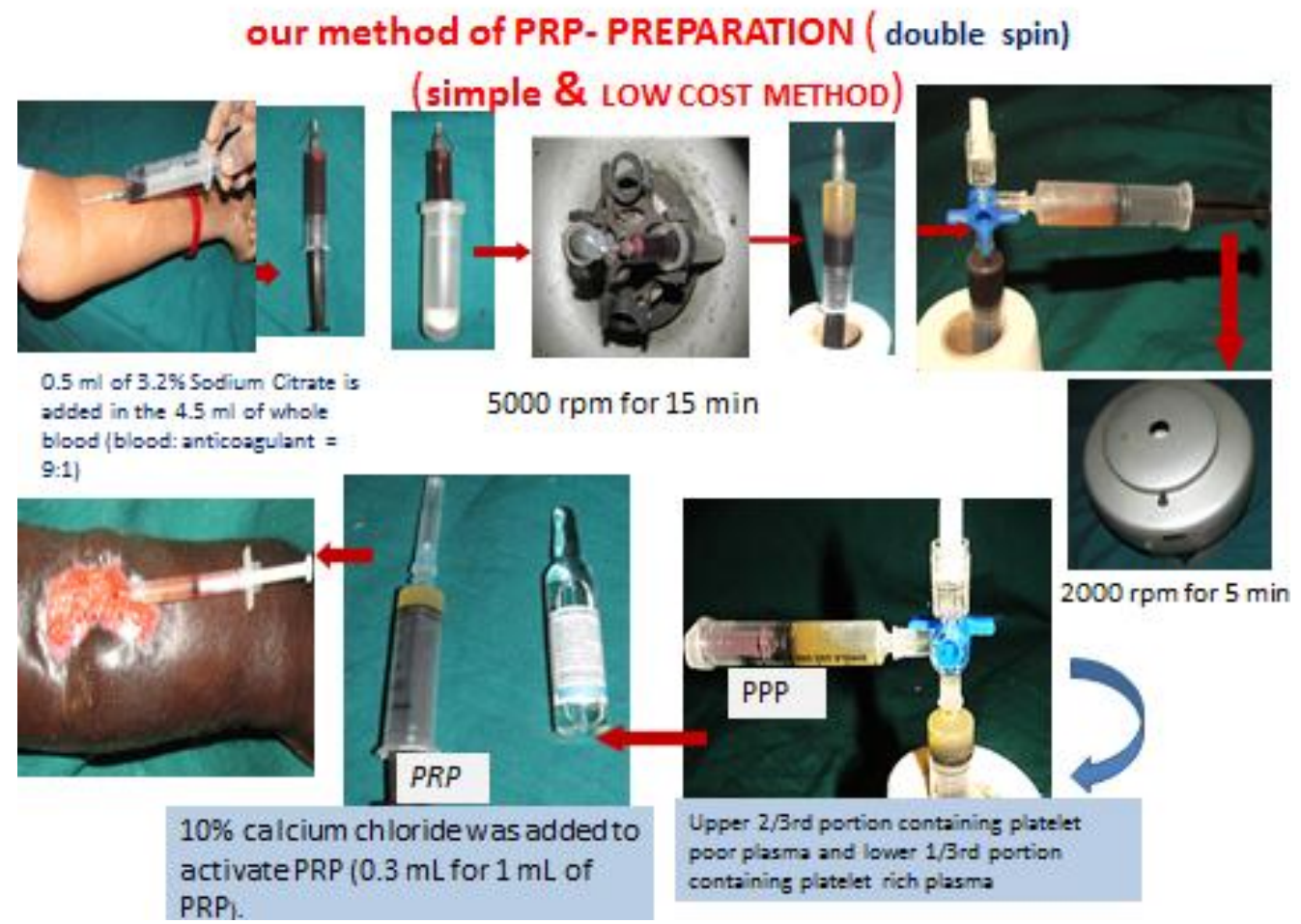

Fig.1 PRP preparation

\section{our method of PRP-PREPARATION}

Blood-platelet -3 laks/cumm

PRP- 12 laks/cumm

\section{Concentration factor 4 time}

\section{Study Design And Measurements:-}

This study is designed as a prospective, randomized-controlled clinical study. Patients would be randomly assigned to two groups, A (experimental group, $\mathrm{n}=20$ ) and $\mathrm{B}$ (control group, $\mathrm{n}=20$ ) Detailed history was taken in all cases regarding the duration, mode of onset, progression, and associated symptoms. Also the etiological factor responsible was elicited in the history.

Ulcer examination was done in all this patients and wound was assessed of its characteristics and photographed. Ulcer was assessed by the investigator at the beginning of the study and at the end of the study; Size of the wound was charted by tracing the edge of wound over the graph on day 1, 7, 14, and 21 day. 


\section{Dressing Technique:-}

After allotting the dressing with the help of random number table, the following procedure was performed.

\section{For conventional Dressing:-}

A chronic non healing ulcer with no active pus discharge and slough was cleaned with the $0.9 \%$ saline solution and was covered with pad and roller bandage

\section{For Autologous Platelet rich plasma:-}

Autologous platelet rich plasma was prepared from patients own blood and injected periphery and over the ulcer bed using insulin needle $(26 \mathrm{G})$ after cleaning with $0.9 \%$ saline and dressing done using pad and roller bandage.

The dressing was changed every 3rd day; similar dressings done to all the patients to both the groups and the outcome is measured on 7 th 14 th day 21 st day.

Wounds will be assessed and measured (length and width, using a metric tape). Outcome is measured in terms of wound reduction between the two groups. Other wound characteristics, i.e., presence or absence of granulation tissue, pain, color, edges, etc. will be documented. The end point of the study will be complete wound closure either surgery in the form of skin graft or spontaneous closure

\section{Statistical analysis:-}

Unpaired students " $\mathrm{t}$ " test and chi square tests were used to find out the statistical significance. A ' $\mathrm{P}$ ' $<0.05$ was taken as significant

\section{Results:-}

This Study was conducted in Coimbatore medical college hospital Coimbatore and the findings are tabulated. During the study year from January 2015 to December 2015, 40 patients with chronic non healing ulcers were randomized into study (PRP) and control (normal saline) group. These groups were studied for the effect of conventional dressing versus PRP on epithelialization and wound reduction. A total of 40 patients satisfied the selection criteria, analysis was done by using students paired ' $t$ ' test for continuous variables within the groups and unpaired ' $t$ ' test for continuous variables between cases and controls.

The efficacy of PRP was compared with control group as the percentage of ulcer surface area covered by granulation tissue. In PRP group had73.86\% mean granulation tissue their ulcer. The control group had $49.1 \%$ mean granulation tissues. The Split Skin Graft uptake was much better in the PRP dressing group $84.789 \% \pm 4.391$ than the normal saline dressing group $68.75 \% \pm 5.718$ which was statistically significant. The mean hospital stay was also significantly lesser in the study group than the control group. 


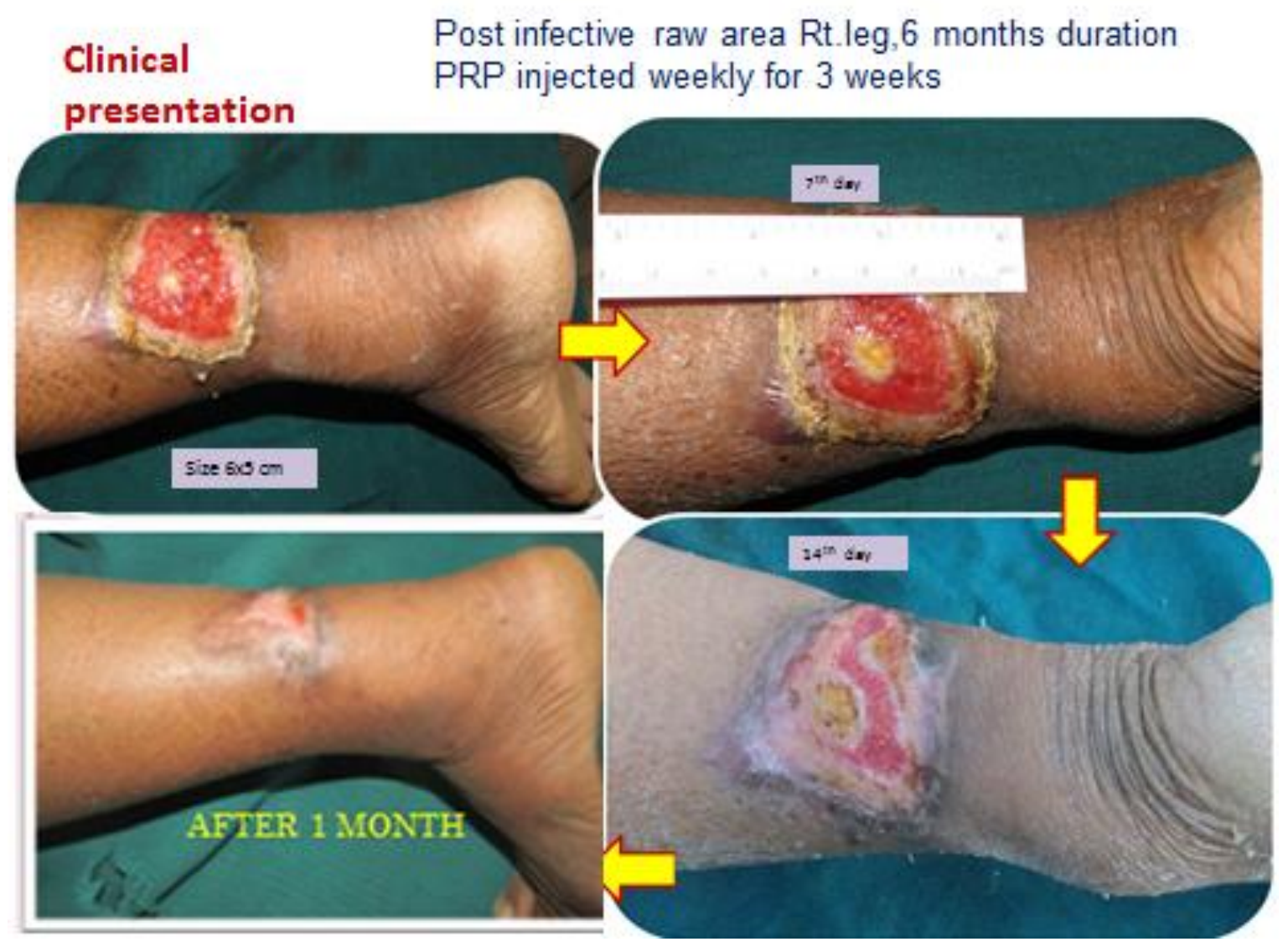

Fig 2:- Clinical Case-acase of non healing ulcer over leg treated with PRP. 
chronic unstable ulcer-2 yrs duration, treated with PRP with skin graft

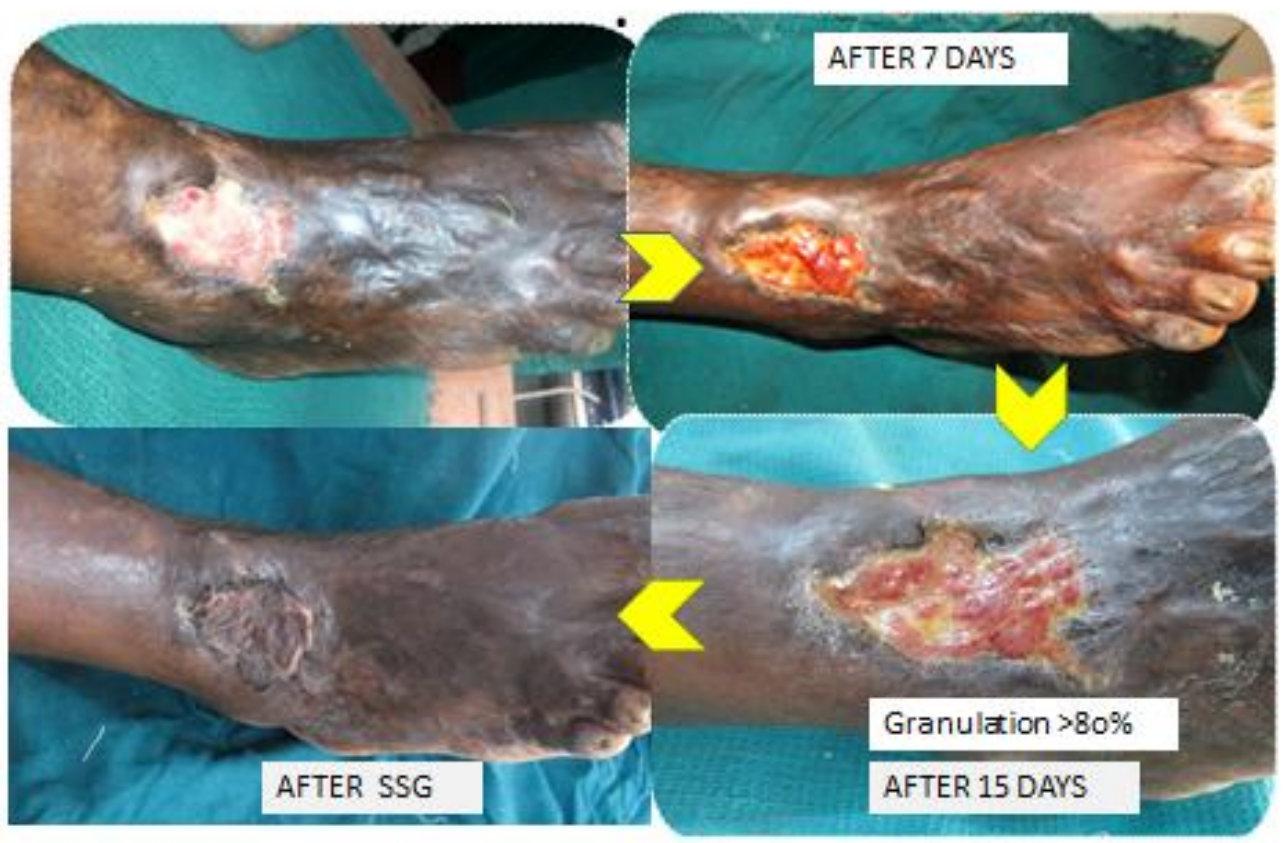

Fig 3:-

Diabetic foot right. Side- 6 months duration treated with PRP

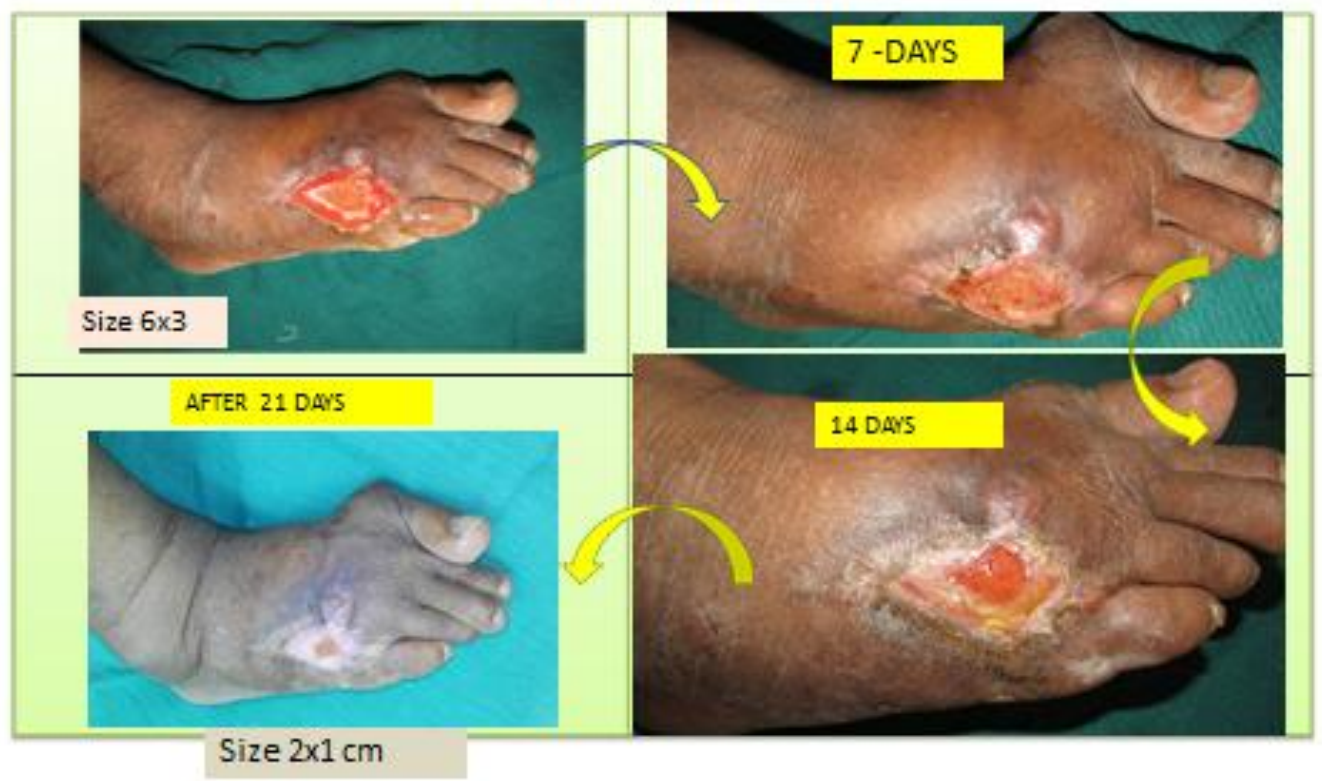

Fig 4:- 


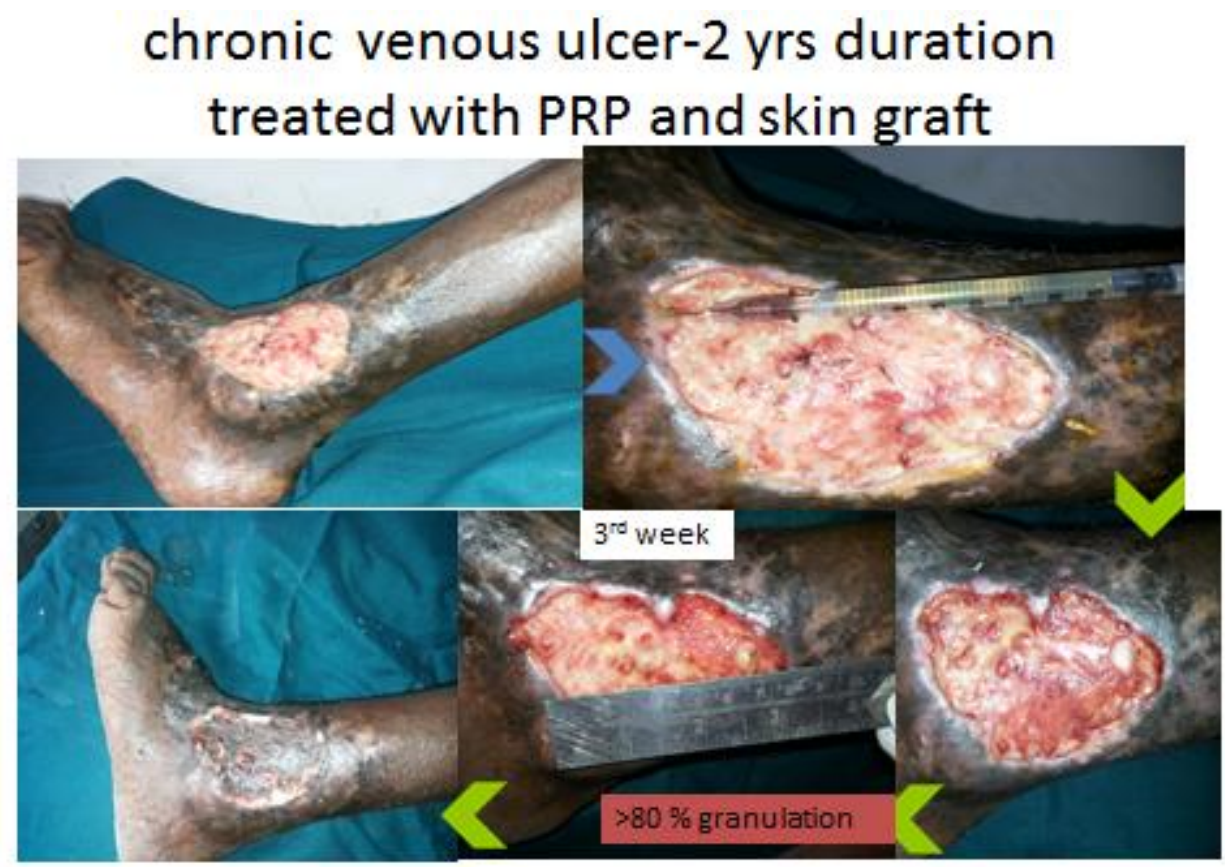

Fig 5:-

Chronic unstable ulcer 3 yrs duration, failed skin

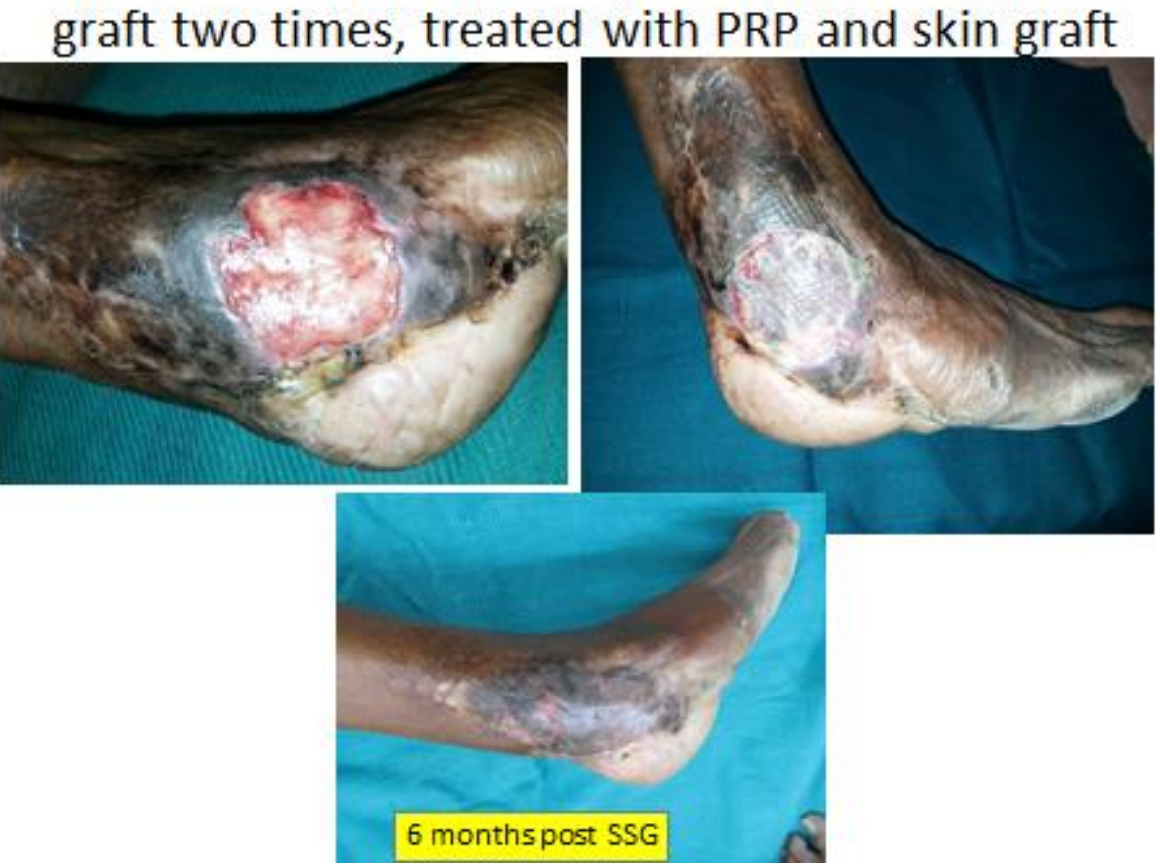

Fig 6:- 


\section{Discussion:-}

Chronic wounds are a major health problem in developing countries like India, and these wounds lack the necessary GFs for healing, they are often difficult to heal and associated with super added infection. PRP contains various necessary growth factors for wound healing. In addition, the high concentration of WBC's present in PRP is also helpful in preventing infections.[13]

In the present study, an attempt has been made to establish better healing rates with use of PRP in chronic non healing ulcers. In this study the baseline characteristics such as age, sex and location of the ulcer were similar in the patients who received PRP dressing in study group and in patients who received control (NS) dressing.

In the present study the mean platelet count was 2, 00,000 in both PRP group and NS group but the PRP yield 3-4 times higher than baseline value of platelet counts.

In this study, initial area of the ulcer $\left(\right.$ in $\mathrm{mm}^{2}$ ) was similar between the two groups. However, the final area of the ulcer (in $\mathrm{mm}^{2}$ ) was significantly reduced in patients with PRP group as compared to the patients in NS group at the end of the study. The percentage reduction in the area of the ulcer was more in the PRP group as compared to the NS group and this difference was statistically significant.

A study conducted by Frykberg et al.[14] on 49 patients with 65 non healing ulcers showed that 63 of 65 ulcers responded with a reduction in area, volume of the ulcers in a mean duration of 2.8 weeks with 3.2 treatments.

Steenvoorde et al.[15] conducted a study on 12 patients with 13 wounds, showing that 7 of 13 wounds required more than 1 application, with a mean number of 2.2 applications and a mean treatment period of 4.2 weeks.

Kakudo et al.[16] treated five cases of intractable skin ulcer with autologous PRP, among which three ulcers healed completely within 4 weeks and epithelization of wound occurred within 6.6 weeks on average.

In our study, 20 patients were treated with PRP and the mean reduction of the ulcers was 30.56\%(SD5.6) in three weeks. We also noticed increase granulation tissue of the wound around $73 \%$ in three weeks and reduced pain and infection

Till now there is no standard method of preparation of PRP in literature. According to Marx, the device must use a double centrifugation technique.[17] Regardless of the rate of centrifugation or the time of centrifugation, a single spin cannot adequately concentrate platelets, because the red blood cells will interfere with their fine separation. Currently, PRP was found to be useful in treating chronic leg ulcers.

\section{Limitations of our study:-}

1. Follow up is short to derive conclusion on long term healing of ulcers.

2. Need further controlled, randomized prospective clinical trials are necessary to definitively demonstrate its efficacy.

3. There is also a need for the development of a standard protocol for the preparation of PRP, as literature currently there is no standardization of the procedure.

\section{Conclusion:-}

We believe that the application of of AUTOLOGUS PLATELET RICH PLASMA (PRP) dressings in comparison with the control group (normal saline group) for the treatment of chronic ulcers of the lower limb, the following conclusions were derived

1. PRP showed faster and better healing rates among the study group.

2. Ulcer area reduction and percentage reduction of ulcer was better in PRP group.

3. Formation of granulation over the ulcer better with PRP group

4. Uptake of skin graft better in PRP group than NS group

5. Skin graft stability and compliance better in PRP group.

6. There were no adverse effects or reactions seen when autologous PRP was applied over the ulcer. 


\section{References:-}

1. Crovetti G, Martinelli G, Issi M, Barone M, Guizzardi M, Campanati B et al. Platelet gel for healing cutaneous chronic wounds. Transfus Apheres Sci 2004 Apr;30(2):145-151. [PubMed] [CrossRef)

2. Cancela AM, Lana JF, Annichino-Bizzachi JM, Belangero WD, Luzo AC. Use of Platelet-Rich Plasma (PRP) in Treating Chronic Wounds. In: Lana JF, et al. (eds.), Platelet-Rich Plasma. Lecture Notes in Bioengineering. Springer-Verlag Berlin, Heidelberg. 2014; p281-288. [CrossRef]

3. Marx RE Platelet-rich plasma (PRP): what is PRP and what is not PRP? Implant Dent. 2001 Dec; 10(4):225228. [PubMed] [CrossRef]

4. Bennett SP, Griffiths GD, Schor AM, Leese GP, Schor SL. Growth factors in the treatment of diabetic foot ulcers. Br J Surg. 2003 Feb; 90(2):133-146. [PubMed] [CrossRef]

5. Fu X, Li X, Cheng B, Chen W. Sheng Z. Engineered growth factors and cutaneous wound healing: Success and possible questions in the past 10 years. Wound Repair Regen. 2005 Mar- pr;13(2):122-130. [PubMed] [CrossRef]

6. Lana JF, Weglein A, Vicente E, Perez AG, Rodrigues AA, Luzo AC, at al. Platelet Rich Plasma and Its Growth Factors: The State of the Art. In: Lana JF, et al. (eds.), Platelet-Rich Plasma. Lecture Notes in Bioengineering. Springer-Verlag Berlin, Heidelberg. 2014; p1-59. [CrossRef]

7. Mehta S,Watson JT. Platelet rich concentrate: basic science and current clinical applications. J Orthop Trauma. 2008;22(6):432-8.

8. Marx RE. Platelet-rich plasma (PRP): what is PRP and what is not PRP? Implant Dent. 2001;10(4):225-8.

9. Driver VR, Hanft J, Fylling CP, Beriou JM,Autologel Diabetic Foot Ulcer Study Group. A prospective, randomized, controlled trial of autologous platelet-rich plasma gel for the treatment of diabetic foot ulcers. Ostomy Wound Manage. 2006;52(6):68-70, 72, 74 passim.

10. Virchenko O, Aspenberg P. How can one platelet injection after tendon injury lead to a stronger tendon after 4 weeks? Interplay between early regeneration and mechanical stimulation. Acta Orthop. 2006 Oct; 77(5):806812. [PubMed] [CrossRef]

11. Weibrich G, Kleis WKG, Hafner G, Hitzler WE. Growth factor levels in platelet-rich plasma and correlations with donor age, sex, and platelet count. J Craniomaxillofacial Surg.2002 Apr; 30(2):97-102. [PubMed] [CrossRef]

12. Driver VR, Hanft J, Fylling CP, Beriou JM. A prospective, randomized, controlled trial of autologous plateletrich plasma gel for the treatment of diabetic foot ulcers. Ostomy Wound Manage. 2006 Jun; 52(6):68-

13. .Marx RE. Platelet-rich plasma (PRP): what is PRP and what is not PRP? ImplantDent

14. Frykberg RG, Driver VR, Carman D, Lucero B, Borris-Hale C, Fylling CP, Rappl LM, Clausen PA. Chronic wounds treated with a physiologically relevant concentration of platelet-rich plasma gel: a prospective case series. Ostomy Wound Manage 2010;56:36-44.

15. Steenvoorde P, van Doorn LP, Naves C, Oskam J. Use of autologous plateletrich fibrin on hard-to-heal wounds. J Wound Care 2008;17:60-3

16. Kakudo N, Kushida S, Ogura N, Hara T, Suzuki K. The use of autologous platelet rich plasma in the treatment of intractable skin ulcer. Open J Reg Med 2012;1:29-32

17. Dohan DM, Choukroun J, Diss A, Dohan SL, Dohan AJ, Mouhyi J, Gogly B. Platelet-rich fibrin (PRF): a second-generation platelet concentrate. Part III leucocyte activation: a new feature for platelet concentrates? Oral Surg Oral Med Oral Pathol Oral Radiol Endod 2006;101:e51-5. 